University of Nebraska - Lincoln

DigitalCommons@University of Nebraska - Lincoln

Faculty Publications from the Department of Engineering Mechanics

\title{
$5-2011$
}

\section{Supramolecular Nanolayer Reconfiguration after Molecular Intercalation}

\author{
Alexandre Dhôtel \\ University of Nebraska-Lincoln \\ Hui Li \\ University of Nebraska-Lincoln, hli4@unl.edu \\ Lucia Fernandez-Ballester \\ University of Nebraska - Lincoln, lucia.fernandez@unl.edu \\ Laurent Delbreilh \\ Université de Rouen \\ Boulos Youssef \\ Université de Rouen \\ See next page for additional authors
}

Follow this and additional works at: https://digitalcommons.unl.edu/engineeringmechanicsfacpub

Part of the Mechanical Engineering Commons

Dhôtel, Alexandre; Li, Hui; Fernandez-Ballester, Lucia; Delbreilh, Laurent; Youssef, Boulos; Zeng, Xiao Cheng; and Tan, Li, "Supramolecular Nanolayer Reconfiguration after Molecular Intercalation" (2011). Faculty Publications from the Department of Engineering Mechanics. 79.

https://digitalcommons.unl.edu/engineeringmechanicsfacpub/79

This Article is brought to you for free and open access by the Mechanical \& Materials Engineering, Department of at DigitalCommons@University of Nebraska - Lincoln. It has been accepted for inclusion in Faculty Publications from the Department of Engineering Mechanics by an authorized administrator of DigitalCommons@University of Nebraska - Lincoln. 
Authors

Alexandre Dhôtel, Hui Li, Lucia Fernandez-Ballester, Laurent Delbreilh, Boulos Youssef, Xiao Cheng Zeng, and Li Tan 


\title{
Supramolecular Nanolayer Reconfiguration after Molecular Intercalation
}

\author{
Alexandre Dhôtel, ${ }^{1,2}$ Hui Li, ${ }^{3}$ Lucia Fernandez-Ballester, ${ }^{1}$ Laurent Delbreilh, ${ }^{2}$ \\ Boulos Youssef, ${ }^{2,4}$ Xiao Cheng Zeng, ${ }^{3}$ and Li Tan ${ }^{1}$
}

1. Advanced Mechanics and Materials Engineering (AMME) International Laboratory, A-TEAM, Department of Engineering Mechanics and Nebraska Center for Materials and Nanoscience, University of Nebraska-Lincoln, Lincoln, Nebraska 68588, United States

2. Advanced Mechanics and Materials Engineering (AMME) International Laboratory, LECAP, Institut des Matériaux de Rouen, Faculté des Sciences, Université de Rouen, Site du Madrillet, 76801 Saint Etienne du Rouvray Cedex, France

3. Department of Chemistry, University of Nebraska-Lincoln, Lincoln, Nebraska 68588, United States

4. Institut National des Sciences Appliquées de Rouen (INSA), Avenue de l'Université - BP 08, 76801 Saint Etienne du Rouvray Cedex, France

Corresponding authors _ L. Tan 1tan4@unl.edu; L. Fernandez-Ballester 1fernandez-ballester2@unl.edu

\begin{abstract}
We examined the structural reconfiguration after intercalating foreign additives, that is, tetramethoxysilane (TMOS), within already formed supramolecular nanolayers of hexadecyltrimethoxysilane (HDTMS). Our experiments indicated that the newly formed interdigitated structure is a thermodynamically more stable configuration. Even after the HDTMS formed initial bilayer-by-bilayer structures, mixing of these aggregates with foreign additives at room temperature can change the original structure to a more compact configuration (i.e., inter-
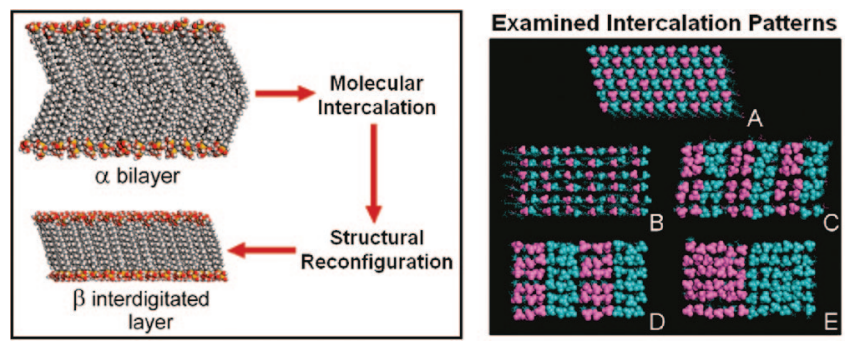
digitated). Our MD simulations further revealed that the most favorable organization for this interdigitated stacking appears to be a formation of relatively small domains of HDTMS and TMOS molecules, supporting our proposal of a heterogeneous mixing before reorganization. Although the coassembly of binary or multiple building blocks has previously been used to modify a supramolecule or to produce a supramolecular composite, the modification of already formed supramolecules via molecular intercalation, examined here, provides a flexible path for decorating more advanced supramolecules without disturbing their complex assembly conditions.
\end{abstract}

\section{Introduction}

Supramolecules are molecularly engineered nanomaterials. $(1,2)$ They can attain molecular weights like those of polymers but also have a well-defined molecular packing akin to those of inorganic or metallic lattices. A rich selection of the building blocks and the resulting long-range ordering in packing have largely promoted their use in a wide variety of applications such as molecular recognition, $(3,4)$ flexible electronics,(5) and catalysis.(6) In contrast to the strong interactions commonly seen in regular crystals, the building blocks inside supramolecules are organized via a noncovalent binding, $(1,2)$ including van der Waals forces, hydrogen bonding, or weak electrostatic interactions. While such weak binding contributes to a certain level of ease in processing, the imposition of a thermal or mechanical impact over a supramolecule can potentially displace building blocks or introduce a plastic deformation.(7) Presumably, if we are capable of modifying the interface or configuration of supramolecules, we could potentially change their thermal or mechanical behaviors. For example, we recently found a multilayer (i.e., a two-dimensional (2D) supramol- ecule) that showed metal-like plastic deformation after its interfaces were modified by performing a coassembly of bulky additives with the primary building blocks. When an external load was applied, the nanolayers showed staircase-like deformation with a $275 \mathrm{~J} / \mathrm{g}$ specific energy absorption or toughness.(8) While such a coassembly of two different building blocks together led to a lightweight counterpart to metal alloys, offering substantial advantages in protecting aero structures or human bodies with minimum weight, we have very limited knowledge on possible structural reconfigurations after the additives were intercalated into the supramolecules.

We have chosen freestanding and long-range ordered 2D supramolecules or nanolayers as our target system in which the primary building blocks are hexadecyltrimethoxysilane (HDTMS). Because of their amphiphilic nature, HDTMS can form a 2D crystal with layered stacking.(9) Particularly, hydrophobic interactions between the hexadecyl chains maximize the exposure of the silane heads to the aqueous environment, thereby forming micelle-like nuclei or aggregates with alternating organic and inorganic layers.(10) This construction, followed by continued stacking along the surface 
normal, delivers a bilayer-by-bilayer lamellar structure.(1113) Since hydrolysis of these silanes could promote the formation of hydrogen bonds among the silanols, $(14,15)$ here we take advantage of the weakness and reversibility of such weak bonds to allow foreign additives, that is, tetramethoxysilane (TMOS), to be intercalated within these already formed HDTMS nanolayers and to monitor possible structural reconfigurations. In the end, we expect a thermally more stable lamellar structure through the formation of covalent bonds among the inorganic moieties.(15)

It is worthwhile to note that a binary system similar to ours has been selected by other groups(16) for a one-step construction where C16TES (hexadecyltriethoxysilane) and TEOS (tetraethoxysilane) are mixed together to form a supramolecular system (C16TES + TEOS $\Rightarrow$ supramolecules). In contrast, we use a two-step strategy, that is, HDTMS $\Rightarrow$ supramolecules $1+\mathrm{TMOS} \Rightarrow$ supramolecules 2 , to examine the reconfiguration capability of those already formed supramolecules. Our molecular dynamics (MD) modeling further suggests that this two-step heterogeneously mixed system is more energy favorable than the one-step well-mixed counterparts.(16)

\section{Experimental Section}

Materials. Hexadecyltrimethoxysilane (technical, $\geq 85 \%$ ) was purchased from Fluka. Tetramethoxysilane ( $\geq 99 \%)$, hydrogen peroxide, and sulfuric acid were purchased from Sigma-Aldrich. Tetrahydrofuran (THF) was purchased from Fisher Scientific. All these chemicals were used as received without further purification. The $500 \mu \mathrm{m}$ prime grade 4 " silicon wafers, P(100) 10-20 ohm-cm SSP and P(100) 1-10 ohm$\mathrm{cm}$ DSP, were purchased from University Wafer. After being cut into rectangular pieces $\left(1.0 \times 1.5 \mathrm{~cm}^{2}\right)$, they were brushed with water, sonicated for $15 \mathrm{~min}$ in ethanol and acetone, respectively, and treated with an acid composed of $\mathrm{H}_{2} \mathrm{SO}_{4}$ / $\mathrm{H}_{2} \mathrm{O}_{2}=1: 1$ (volume ratio) for $30 \mathrm{~min}$. Finally, they were copiously rinsed with water and dried under a stream of nitrogen.

Nanolayer Formation and Intercalation. Hexadecyltrimethoxysilane (HDTMS, $0.35 \mathrm{~mL}$ ) was added to a mixture of THF $(7.5 \mathrm{~mL})$, water $(0.05 \mathrm{~mL})$, and hydrochloric acid (2 $\mathrm{M}, 0.9 \mu \mathrm{L})$. The mixture was then stirred at $400 \mathrm{rpm}$ for $3 \mathrm{~h}$ at room temperature to ensure a rather complete hydrolysis of HDTMS (silanes becoming silanols).(17a, 17b) Then, tetramethoxysilane (TMOS, $0.13 \mathrm{~mL})$ dispersed in water $(0.06 \mathrm{~mL})$ was added in a proportion such that the molar ratio among the components was HDTMS/TMOS/THF $/ \mathrm{H}_{2} \mathrm{O} / \mathrm{HCl}=$ 0.85:1:100:7:0.002. The final mixture was then held without stirring for specific period of times (dubbed intercalation time, $t_{i}$, between $1 \mathrm{~min}$ and $24 \mathrm{~h}$ ) before a quick stirring and drop-casting onto a piece of precleaned silicon wafer. The drop-casted film was dried inside a covered Petri dish for $24 \mathrm{~h}$ at room temperature. Control experiments were performed where the same solution and time protocol was used but TMOS additives were not added, producing nanolayers of only HDTMS.

Nanolayer Characterization. Wide- (WAXS) and smallangle X-ray scattering (SAXS) spectra were obtained on a Rigaku D/Max-B Geigerflex diffractometer using a $\mathrm{Cu} \mathrm{Ka}$ $(1.544 \AA)$ radiation and a graphite monochromator. Digital data were recorded at an angular resolution of $0.02^{\circ}$. The thin film samples were analyzed directly on their silicon substrate at an angular velocity of $0.5^{\circ} / \mathrm{min}$. SAXS was recorded from 1 to $14^{\circ}$ on very thin films (a few micrometers). WAXS was recorded from 18 to $28^{\circ}$ on $1 \mathrm{~mm}$ thick films. The Atomic Force Microscope (AFM) Dimension 3100 SPM was used at room temperature to obtain topographic images of the thin films (Supporting Information). Images were recorded at a maximum resolution of 512 lines under a tapping mode. Thermogravimetric analysis (TGA) and differential scanning calorimetry (DSC, Supporting Information) analysis were performed using a STA 6000 (simultaneous thermal analyzer) from Perkin-Elmer with an internal reference balance. TGA/DSC measurements were made from 25 to 800 ${ }^{\circ} \mathrm{C}$ at a heating rate of $5{ }^{\circ} \mathrm{C} / \mathrm{min}$ under a nitrogen flow. The data were recorded at $0.03{ }^{\circ} \mathrm{C}$ intervals. The Fourier transform infrared-attenuated total reflectance (FTIR-ATR) spectra were recorded by using a Nicolet Avatar 360 FT-IR with a SmartPerformer ATR assembly. This machine utilizes a zinc selenide (ZnSe) ATR lens that is IR transparent through 500 $\mathrm{cm}^{-1}$. Acquisitions were performed at a resolution of $4 \mathrm{~cm}^{-1}$. The films were scratched at the substrate surface before being analyzed.

\section{Results and Discussion}

Formation of nanolayers is a consequence of hydrolysis and later polycondensation between the alkylsilane building blocks.(14) HDTMS can be regarded as an ideal candidate for supramolecular assembly because the 16-carbon alkyl chain plus the polar inorganic terminals can create strong hydrophobic and hydrophilic interactions to drive self-organization. $(11,12)$ In our experimental protocol, HDTMS molecules were allowed to get hydrolyzed in an acidic environment for $3 \mathrm{~h}$ before the addition of the second building block (TMOS). This treatment immediately created a solvation contrast between both building blocks in the liquid medium; while TMOS may still prefer solvation by the THF solvent, the formation of aggregates by tightly packed HDTMS molecules is promoted due to the increased polarity after conversion of the methoxy $\left(-\mathrm{OCH}_{3}\right)$ groups into hydroxyl $(-\mathrm{OH})$ ones during hydrolysis.(18) Very likely, this situation could lead to the formation of hydrogen or even some covalent bonds between the hydroxyls (silanols) on HDTMS such that a bilayer-by-bilayer stacking is obtained. Then, after TMOS molecules are hydrolyzed in this acidic environment, they could intercalate into the inorganic portion of these HDTMS aggregates or nanolayers. To evaluate this phenomenon, we define the time interval between the addition of TMOS to the HDTMS solution and the casting onto a silicon wafer as the intercalation time $\left(t_{i}\right)$, which represents the time during which TMOS molecules begin hydrolysis and undergo condensation, either with themselves or within the HDTMS nanolayer, until drop-casting is performed. More interestingly, if extensive insertion of TMOS into the nanolayers occurs, it may provide an opportunity for a stacking reconfiguration of the nanolayers, which is described through the following analysis.

X-ray Diffraction (XRD) Spectra. Packing reconfiguration of the nanolayers is obvious when we record the XRD of drop-cast films obtained after a series of different intercalation times. When a long enough intercalation time $\left(t_{i}>8 \mathrm{~h}\right)$ is given to TMOS, the as-cast thin film clearly shows the formation of a new structure (dubbed $\beta$ structure, corresponding to the peak at $2 \theta$ of $3.2^{\circ}$ in Figure 1 , upper curves). If we consider that the length of each HDTMS molecule is $2.3 \mathrm{~nm}$, the $d$-spacing of the $\beta$ structure (2.8 nm, Figure 2a top) will be too small to pack HDTMS into a bilayer and too big to represent a single layer. As proposed by Bourlinos et al., we ascribe this structure to an interdigitated stacking of the alkyl chains of HDTMS between neighboring layers.(19, 20) More interestingly, the occurrence of this interdigitated layer-bylayer $\beta$ packing comes together with an intensity decrease in 
the a conformation (corresponding to the peak at $2 \theta$ of $2.2^{\circ}$, Figure 1 upper curves). The combination of these two phenomena suggests that the newly formed $\beta$ layers are a direct reconfiguration of the a ones.(17) ${ }^{\mathrm{c}}$

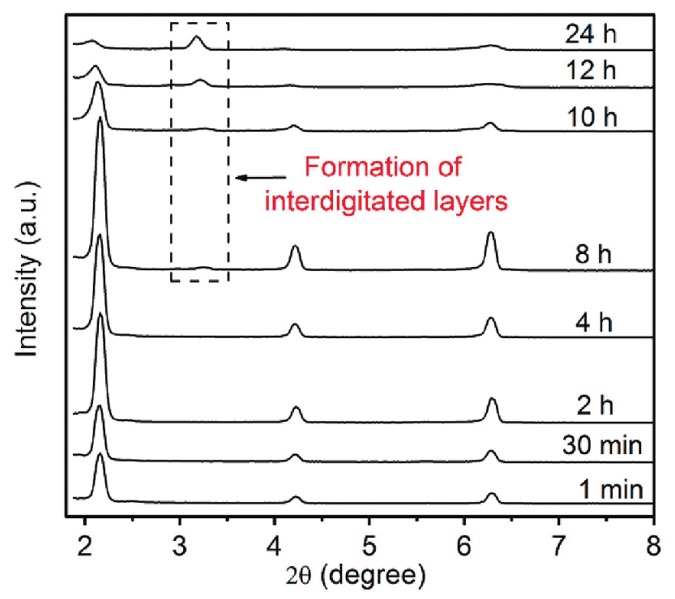

Figure 1. XRD patterns showing structural reconfiguration after molecular additives (TMOS) were inserted into nanolayer-like supramolecules of alkylsilane (HDTMS) for different intercalation times $\left(t_{i}\right)$. For relatively short $t_{i}(\leq 4 \mathrm{~h})$, only a bilayer-by-bilayer structure is observed $\left(d_{001}, d_{002}\right.$, and $d_{003}$ at $2.15,4.22,6.28^{\circ}$, respectively). In contrast, for $t_{i} \geq$ $8 \mathrm{~h}$ new interdigitated layers emerge $\left(2 \theta \sim 3.2^{\circ}\right)$ at the expense of the initial bilayered structure.
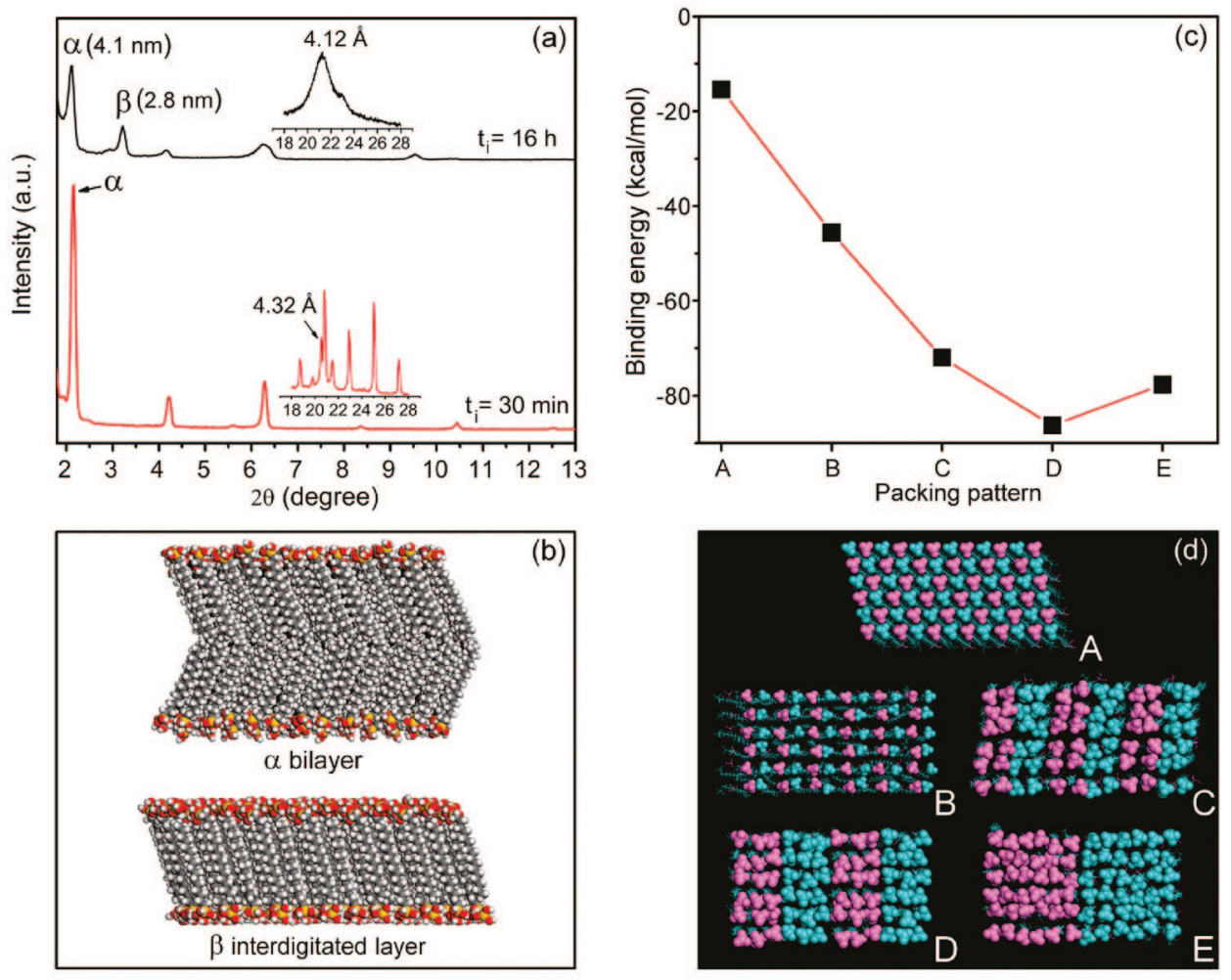

In contrast, when the intercalation time is kept relatively short $\left(t_{i} \leq 4 \mathrm{~h}\right)$, the a conformation is always the dominant stacking structure of the nanolayers (Figure 1, lower curves). Since the $d$-spacing of $4.1 \mathrm{~nm}$ (Figure $2 \mathrm{a}$, bottom) is close to twice the length of a HDTMS molecule, it suggests that the a structure is a head-to-head arrangement of HDTMS $\left(\mathrm{C}_{16} \mathrm{H}_{34} \mathrm{SiO}_{x}-\mathrm{O}_{x} \mathrm{SiC}_{16} \mathrm{H}_{34}\right)$, also known as bilayers. The presence of a large number of higher order diffraction peaks (up to $n=13$, see Supporting Information SI-1) implies the wellordered periodic nature of the bilayered stacking. Also, the wide-angle XRD spectrum (Figure 2a bottom inset) exhibits an extra peak at $2 \theta$ of $20.5^{\circ}$ or $d$-spacing of $4.32 \AA$, which is usually assigned to the spacing between alkyl chains.(813) Because the samples used for WAXS were significantly thicker than those for SAXS, the bottom inset of Figure $2 \mathrm{a}$ also reveals diffraction peaks corresponding to an additional bilayered $\mathrm{a}^{\prime}$ structure with a $d$-spacing of $4.8 \mathrm{~nm}$, somewhat larger than that of the a structure (see Supporting Information SI-1). This a' structure may originate from a variation in the orientation of the alkyl chains, $(12,20)$ or from a distortion of the inorganic network of a layers which can lead to the loss of interlayer correlation between adjacent lamellar planes.(19) When this happens, the gap between the bilayers will increase, causing a greater basal spacing for the overall bilayered structure (evidence of the presence of a' layers in thick films using SAXS is available in Supporting Information SI-2).

By giving $3 \mathrm{~h}$ of hydrolysis time (before TMOS is added, cf. Experimental Section), HDTMS can be assumed to have un-

Figure 2. (a) Wide- and small-angle XRD of nanolayers where molecular additives TMOS are allowed to intercalate into HDTMS for (bottom) $t_{i}=$ $30 \mathrm{~min}$, and (top) $t_{i}=16 \mathrm{~h}$. For $t_{i}=30 \mathrm{~min}$ (a, bottom), only a bilayer-by-bilayer a structure of stacked HDTMS molecules is observed. In the wide angle region (a, bottom inset), the peak at $4.32 \AA$ corresponds to the spacing between alkyl chains in the a structure. For $t_{i}=16 \mathrm{~h}(\mathrm{a}$, top), a new $\beta$ structure appears due to TMOS insertion into HDTMS stacks in addition to the original a layers, causing space widening between alkyl chains or peak broadening in XRD at $4.12 \AA$ (a, top inset). (b) Snapshots of the (top) HDTMS bilayer film and (bottom) mixed HDTMS/TMOS single layer at the end of 1 ns MD simulation. Color code: oxygen (red), silicon (yellow), carbon (gray), and hydrogen (white). (c) Calculated average binding energies of the mixed HDTMS/TMOS interdigitated stacking with five different packing organizations. (d) Top views of the five organizations by MD, where blue and pink balls represent HDTMS and TMOS molecules, respectively. 
dergone a rather complete hydrolysis.(17a, 17b) Furthermore, the observation of a diffraction peak corresponding to a bilayers for a very short intercalation time of $t_{i}=1 \mathrm{~min}$ (Figure 1 , bottom curve), indicates that the hydrolyzed HDTMS molecules have started their arrangement into 2D supramolecular nanolayers before the addition of TMOS. Even when $t_{i}$ is extended to $30 \mathrm{~min}$ and longer $\left(t_{i} \leq 4 \mathrm{~h}\right)$, the final XRD pattern of the HDTMS + TMOS films corresponds to only a bilayers, which is the same structure found in the control experiments of pure HDTMS films where no TMOS has been added (Supporting Information SI-3). In other words, the high contrast between the hydrophilic silanol terminals and the hydrophobic interactions caused by the long alkyl chains of HDTMS, as well as their tight packing inside the nanolayers, hamper a rapid structural reconfiguration via TMOS insertion. Since our XRD shows no evidence of the presence of a separate ordered TMOS structure, TMOS might have formed an amorphous phase among those HDTMS nanolayers.

When the intercalation time is kept sufficiently long $\left(t_{i}>8\right.$ h), a dual-structural packing, composed of bilayered $\alpha$ and interdigitated $\beta$ layers, is formed (Figure $2 \mathrm{a}$, top curve). In contrast, our control samples (no TMOS was added) are composed purely of a bilayers (see Supporting Information SI-4). This indicates that the structural reconfiguration from a bilayers to interdigitated $\beta$ layers is induced by the introduction of TMOS and also that this reconfiguration is not an immediate process. In other words, the use of longer intercalation times has relieved the initial barrier for switching bilayers into a more compact single layered stacking. Similarly to the case of showing an extra a' layered structure, a very small quantity of $\beta^{\prime}$ layers with a $d$-spacing of $3.0 \mathrm{~nm}$, which was slightly larger than that of $\beta$ layers, was found in the film (see Supporting Information SI-5). By the same token as for a' layers, the $\beta^{\prime}$ layers may be ascribed to slipped interdigitated $\beta$ layers. Furthermore, WAXS for $t_{i}=16 \mathrm{~h}$ exhibits two peaks (Figure 2a, top inset): a broad peak centered on $21.3^{\circ}$ ( $d$-spacing of $4.18 \AA$ ) attributed to the spacing between alkyl chains, and another at $23^{\circ}$ (d-spacing of $3.9 \AA$ ) corresponding to the 11 th order of diffraction of the a structure. The breadth of the peak due to alkyl chain spacing here is much wider than the peak found for a shorter intercalation time of $t_{i}=30 \mathrm{~min}$ (Figure 2a, bottom inset). Since the control film formed of pure HDTMS (no TMOS) after an intercalation time of $t_{i}=16 \mathrm{~h}$ also exhibits a broad peak (see Supporting Information SI-4), it suggests that the breadth of this peak is due to condensation. Indeed, the longer intercalation time $\left(t_{i}=16 \mathrm{~h}\right)$ allowed a larger fraction of the molecules in solution to form covalent bonds whose rigidity and directionality may produce a tendency to bring all molecules closer, or even bend and tilt, leading to a wider distribution of alkyl chain spacings. Alternatively speaking, since the $\beta$ structure became prominent only after a long intercalation time, it is reasonable to argue that the extent of the condensation will be much lower in the films cast only after a minimum degree of TMOS insertion (short $t_{i}$ ) than in those where the partial transition to the $\beta$ structure has already occurred (see discussion of FTIR).

Our hypothesis is that TMOS additives can intercalate between groups of tightly packed HDTMS aggregates (dimers, trimers, and so on) among those bilayer-by-bilayer structures. Given enough time and degree of intercalation, this heterogeneous mixing will trigger a structural reconfiguration from the bilayered conformation to an interdigitated one. Previous one-step supramolecular construction performed by other groups(16) using binary building blocks (TEOS and C16TES) suggested that a high temperature is the key parameter to produce fully miscible silanols, thus suppressing
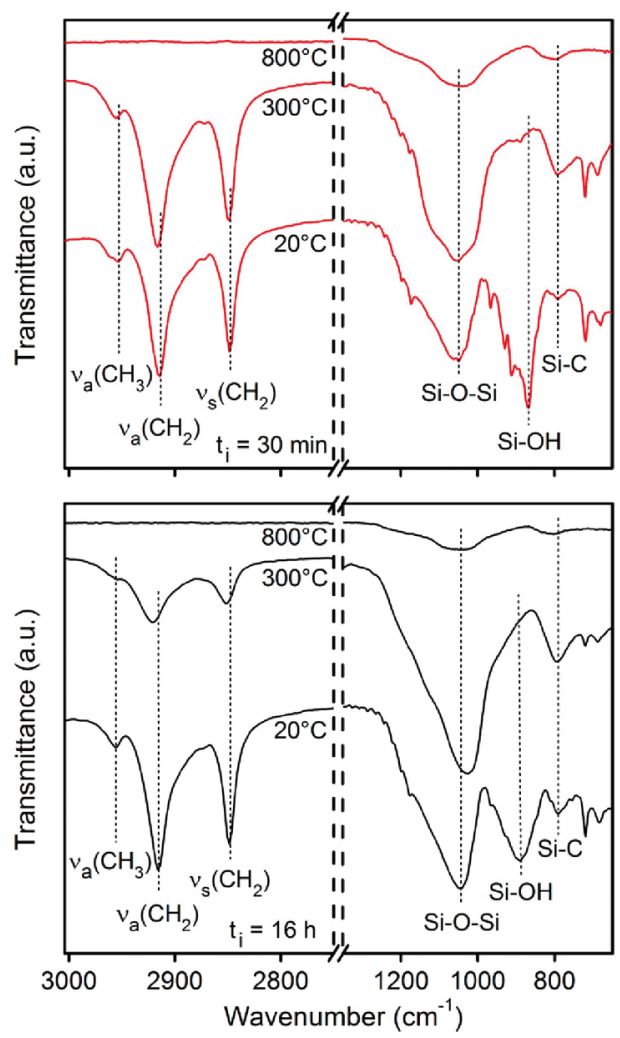

Figure 3. FTIR-ATR spectra of nanolayers for (top) $t_{i}=30 \mathrm{~min}$, and (bottom) $t_{i}=16 \mathrm{~h}$ at $20{ }^{\circ} \mathrm{C}$ and after heat treating at 300 and $800{ }^{\circ} \mathrm{C}$ under $\mathrm{N}_{2}$ environment. Virgin nanolayers indicate that condensation has occurred to larger extent for the longer $t_{i}=16 \mathrm{~h}$ (presence of condensed silanols, $\left.\mathrm{Si}-\mathrm{O}-\mathrm{Si}, 1064 \mathrm{~cm}^{-1}\right)$, but that overall condensation is still rather incomplete (significant presence of hydrolyzed silanols, $\mathrm{Si}-$ $\left.\mathrm{OH}, 890 \mathrm{~cm}^{-1}\right)$. Alkyl chains are revealed by the alkyl groups $(2848$, and $2914 \mathrm{~cm}^{-1}$ ) and alkylsilane linkage $\left(\mathrm{Si}-\mathrm{C}, 794 \mathrm{~cm}^{-1}\right)$. Heat treatment at $300{ }^{\circ} \mathrm{C}$ produces extensive conversion from silanols $(\mathrm{Si}-\mathrm{OH})$ to siloxanes ( $\mathrm{Si}-\mathrm{O}-\mathrm{Si})$, while heat treatment at $800{ }^{\circ} \mathrm{C}$ shows removal of alkyl components and the robustness of left-over silicon oxides.

segregation, before the final formation of interdigitated $\beta$ layers. While that mechanism may still hold true for kinetic reasons, our two-step experiments indicate that the interdigitated structure is intrinsically a thermodynamically more stable configuration. Even after the bilayer-by-bilayer structures are already formed, heterogeneous mixing with foreign additives at room temperature can change the original a structure to the more compact $\beta$ configuration. Essentially, this confirms earlier work by Metternich et al.(21) that these silanols (i.e., silanol, silanediol, or silanetriol) cannot undergo a complete condensation even long after their initial hydrolysis. Rather, silanols could mostly be held together by hydrogen bonds whose reversibility makes our observed reorganization possible. To partially support this hypothesis, we performed molecular dynamics (MD) simulation in a constant-pressure and constant-temperature (NPT) ensemble. The temperature is controlled at $300 \mathrm{~K}$, and the external pressure is set at $1 \mathrm{~atm}$. The consistent valence force field (CVFF) is selected to describe interactions among the molecules. The MD simulation indicates that the thicknesses for the HDTMS bilayer (Figure 2b, top) and for HDTMS aggregates/TMOS interdigitated layer (Figure $2 \mathrm{~b}$, bottom) are 45.0 and $31.5 \AA$, respectively, in close agreement with our experimental results. If we consider some HDTMS molecules forming aggregates with each other via covalent bonds inside the $\beta$ configuration, we can examine average binding 


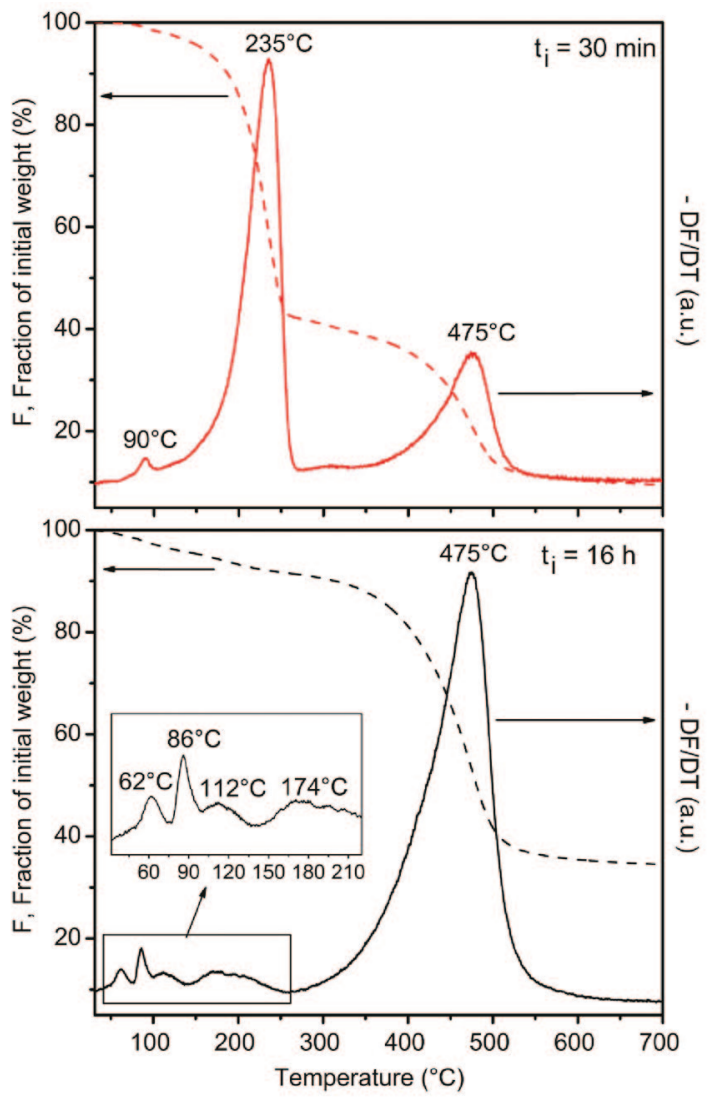

Figure 4. TGA of molecularly intercalated nanolayers. The sample with shorter intercalation time (top, $t_{i}=30 \mathrm{~min}$ ) has two major weight losses at $235^{\circ} \mathrm{C}$ (removal of weakly bonded alkylsilane molecules) and $475{ }^{\circ} \mathrm{C}$ (removal of alkyl components), respectively. The extensively intercalated sample (bottom, $t_{i}=16 \mathrm{~h}$ ) has only one significant weight loss at $475^{\circ} \mathrm{C}$. Inset in bottom panel shows multiple peaks for removal of tetrahydrofuran $\left(62^{\circ} \mathrm{C}\right)$, methanol $\left(86^{\circ} \mathrm{C}\right)$, physically bonded water $\left(112^{\circ} \mathrm{C}\right)$, and chemically bonded water $\left(174^{\circ} \mathrm{C}\right)$.

energy (per molecule) among five different organizations, all shown in Figure $2 \mathrm{c}, \mathrm{d}$. We found that the well mixed HDTMS/TMOS organization whose top view is like a checkerboard (A) is not the most stable configuration due to unfavorable binding. Similarly, the organization in which the HDTMS and TMOS molecules are separated by relatively large HDTMS and TMOS domains (E) is not the most advantageous either. Our simulations revealed that the most favorable organization for the interdigitated $\beta$ structure appears to be a formation of relatively small interdispersed domains of HDTMS and TMOS molecules (D), supporting our proposal of a heterogeneous mixing before reorganization.

Fourier Transform Infrared-Attenuated Total Reflectance Spectra. The type of bonding in as-assembled films can be characterized by their absorption peaks in FTIR-ATR spectra. The peaks at 2955, 2914, and $2848 \mathrm{~cm}^{-1}$ (Figure 3, left) were respectively assigned to the asymmetric $\mathrm{CH}_{3}$, asymmetric, and symmetric $\mathrm{CH}_{2}$ stretching modes. $(20,22,23)$ The slight shift of $\mathrm{v}_{\mathrm{s}}\left(\mathrm{CH}_{2}\right)$ and $\mathrm{v}_{\mathrm{a}}\left(\mathrm{CH}_{2}\right)$ to higher wave numbers as the temperature is increased from 20 to $300{ }^{\circ} \mathrm{C}$ (for both intercalation times) indicates a transition from a chain-ordered state to a chain-disordered state probably caused by the formation of gauche defects in alkyl chains between those temperatures.(24) The peaks corresponding to the covalent bonds of inorganic moieties Si-O-Si and Si-C (Figure 3, right) are at 1064 and $794 \mathrm{~cm}^{-1}$, respectively.(23, 25) While the pres- ence of a Si-O-Si peak for films at $20^{\circ} \mathrm{C}$ for both intercalation times indicates that some condensation has occurred, the relatively high intensity of the $\mathrm{Si}-\mathrm{OH}$ peak at $890 \mathrm{~cm}^{-1}\left(20^{\circ} \mathrm{C}\right.$ curves), on the other hand, indicates an incomplete condensation between molecules, $(11,19)$ confirming that under our experimental conditions condensation of molecules is a rather slow process. Consequently, the self-assembled molecules were held together mostly by hydrogen bonds between hydroxyl groups even for long intercalation time specimens that made possible the reconfiguration of the bilayered structure by TMOS. It must be noted, however, that the fraction of inorganic moieties that have undergone condensation is larger for samples at $t_{i}=16 \mathrm{~h}$ than that at $t_{i}=30 \mathrm{~min}$.

After heating up to $300{ }^{\circ} \mathrm{C}$, both films showed an increase of the $\mathrm{Si}-\mathrm{O}-\mathrm{Si}$ peak at the expense of the $\mathrm{Si}-\mathrm{OH}$ peak, indicating that condensation of the inorganic moieties is promoted by raising the temperature. After further heating up to $800{ }^{\circ} \mathrm{C}$ (Figure 3, top curves), both films showed disappearance of all carbon-hydrogen peaks, suggesting degradation of HDTMS by releasing the alkyl components before $800{ }^{\circ} \mathrm{C}$. Since the peaks responsible for $\mathrm{Si}-\mathrm{O}-\mathrm{Si}$ and $\mathrm{Si}-\mathrm{C}$ absorptions are still present, it indicates their larger robustness when compared with $\mathrm{C}-\mathrm{C}$ type bonds. Indeed, the bond dissociation energy for C-C bonds at $298 \mathrm{~K}$ is $\sim 70 \mathrm{kcal} / \mathrm{mol}(26)$ and 94.2 and 136 $\mathrm{kcal} / \mathrm{mol}$ for $\mathrm{Si}-\mathrm{C}$ and $\mathrm{Si}-\mathrm{O}-\mathrm{Si}$, respectively. $(27,28)$

Thermogravimetric Analysis. TGA reveals an enhanced thermal stability of the interdigitated layers for our system. While two main degradation temperatures $\left(235\right.$ and $\left.475^{\circ} \mathrm{C}\right)$ are present for films of $t_{i}=30 \mathrm{~min}$ (Figure 4 top), the specimens with $t_{i}=16 \mathrm{~h}$ experience only one substantial degradation at $475^{\circ} \mathrm{C}$ (Figure 4 bottom). The second main degradation (at $475^{\circ} \mathrm{C}$ ) is typically attributed to the degradation of alkyl chains, $(11,29)$ consistent with the FTIR-ATR spectra above showing peaks for inorganic network ( $\mathrm{Si}-\mathrm{C}$ and $\mathrm{Si}-\mathrm{O}-\mathrm{Si}$ ) only after heating from 300 to $800^{\circ} \mathrm{C}$. If we consider that the former sample $\left(t_{i}=30 \mathrm{~min}\right)$ has a more significant fraction of molecules being still held together by hydrogen bonds, the degradation at a relatively low temperature of 235 ${ }^{\circ} \mathrm{C}$ could be ascribed to the release of those free molecules. (20) Additionally, the latter sample $\left(t_{i}=16 \mathrm{~h}\right)$, which has a significant portion of molecules interdigitally packed, will be rendered with limited molecular motions. As a consequence, those weakly bonded molecules are hard to release; instead, they might be forced to engage in further condensation, evidenced by a larger ultimate residual weight fraction (34 wt $\%$ ) comparing to that (9 wt \%) with a short intercalation time as shown in Figure 4.

There are peaks showing molecular removal at lower temperatures (before $180{ }^{\circ} \mathrm{C}$ ), for instance, THF at $62^{\circ} \mathrm{C}$, weakly bonded water from the inorganic network at $112^{\circ} \mathrm{C},(11)$ and water byproduct from the condensation between $\mathrm{Si}-\mathrm{OH}$ groups at $174{ }^{\circ} \mathrm{C}$.(11) While the peak at $86-90{ }^{\circ} \mathrm{C}$ might be another indicator for the structural reorganization in nanolayers, the exothermic nature of the peak on DSC curve (cf. Supporting Information SI-7) suggests that it may be due to removal of another byproduct, i.e., methanol $\left(\mathrm{CH}_{3} \mathrm{OH}\right)$, from the condensation process.

\section{Conclusions}

We examined the structural reconfiguration induced by intercalating foreign additives (TMOS) within already formed supramolecular nanolayers of HDTMS. Our twostep experiments indicate that the interdigitated structure is a thermodynamically more stable configuration. Even after 
the initial HDTMS bilayer-by-bilayer structures are already formed, the heterogeneous mixing of them with foreign additives (TMOS) at room temperature can change the original $\alpha$ structure to the more compact $\beta$ configuration. This suggests that silanols do not undergo a complete condensation even long after their initial hydrolysis. Rather, aggregates of them were held together by hydrogen bonds whose reversibility makes our observed structural reorganization possible. Our MD simulations further revealed that the most favorable organization for the interdigitated structure appears to be a formation of relatively small interdispersed domains of HDTMS and TMOS molecules, supporting our proposal of a heterogeneous mixing before reorganization. Although coassembly of binary or multiple building blocks together have been previously used to modify a type of supramolecule or give rise to a lightweight counterpart to metal alloys, the results reported here suggest that for our 2-step pathway the coassembly or intercalation does not happen immediately. Indeed, only when the intercalation time is sufficiently long (over $8 \mathrm{~h}$ ), a significant degree of coassembly will start, accompanied by a structural reconfiguration.

Acknowledgments - We are grateful to the partial financial support from Partner University Fund (PUF) between UNL and UR, the National Science Foundation (CMMI 1068952, 0900644, 0825905), and the Army Research Office (W911NF-08-1-0190). A.D. is also grateful to Sara Basiaga and Jonathan Hein for their generous help in DSC/TGA and FTIR.

Supporting Information (following References) includes the following:

SI-1 - SI-4: XRD spectra of HDTMS + TMOS films at $t_{i}=$ $30 \mathrm{~min}$ (thin and thick films), pure HDTMS films at $t_{i}=$ $30 \mathrm{~min}$, and $16 \mathrm{~h}$.

SI-5: Zoom-in of Figure 2a top curve.

SI-6: AFM images of HDTMS + TMOS film at $t_{\mathrm{i}}=16 \mathrm{~h}$.

SI-7: DSC of HDTMS + TMOS film at $t_{i}=30 \mathrm{~min}$.

Schematic of HDTMS and TMOS alcohol condensation reactions.

\section{References}

(1) Lehn, J. M. Angew. Chem., Int. Ed. 1990, 29, 1304-1319.

(2) Lehn, J. M. Science 1993, 260, 1762-1763.

(3) Matile, S. Chem. Soc. Rev. 2001, 30, 158-167.

(4) Ganjali, M. R.; Norouzi., P.; Rezapour., M.; Faridbod., F.; Pourjavid., M. R. Sensors 2006, 6, 1018-1086.

(5) Kim, Y. H. J. Nanosci. Nanotechnol. 2008, 8, 4593-4597.

(6) Chen, B. L.; Xiang., S. C.; Qian., G. D. Acc. Chem. Res. 2010, $43,1115-1124$.

(7) Tan, J. C.; Bennett., T. D.; Cheetham., A. K. Proc. Natl. Acad. Sci. U.S.A. 2010, 107, 9938-9943.

(8) Yu, C.; Chen, Z.; Li, H.; Turner, J.; Zeng, X. C.; Jin, Z.; Jiang, J.; Youssef, B.; Tan, L. Adv. Mater. 2010, 22, 4457.

(9) Mattu, J.; Johansson, T.; Holdcroft, S.; Leach, G. W. J. Phys. Chem. B 2006, 110, 15328-15337.

(10) Stephenson, B. C.; Goldsipe, A.; Beers, K. J.; Blankschtein, D. J. Phys. Chem. B 2007, 111, 1025-1044.

(11) Parikh, A. N.; Schivley, M. A.; Koo, E.; Seshadri, K.; Aurentz, D.; Mueller, K.; Allara, D. L. J. Am. Chem. Soc. 1997, 119, 3135-3143.
(12) Shimojima, A.; Sugahara, Y.; Kuroda, K. Bull. Chem. Soc. Jpn. 1997, 70, 2847-2853.

(13) (a) Jiang, J.; Lima,O.; Pei, Y.; Jiang, Z.; Chen, Z.; Yu, C.;Wang, J.; Zeng, X.; Forsythe, E.;Tan, L. ACS Nano 2010, 4, 3773-3780. (b) Jiang, J.; Lima, O.; Pei, Y.; Zeng, X.; Tan, L.; Forsythe, E. J. Am. Chem. Soc. 2009, 131, 900-901.

(14) Brinker, C. J. J. Non. Cryst. Solids 1988, 100, 31-50.

(15) Kim, H. K.; Lee, J. P.; Park, C. R.; Kwak, H. T.; Sung, M. M. J. Phys. Chem. B 2003, 107, 4348-4351.

(16) Shimojima, A.; Kuroda, K. Langmuir 2002, 18, 1144-1149.

(17) (a) Brand, M.; Frings, A.; Jenkner, P.; Lehnert, R.; Metternich, H. J.; Monkiewicz, J.; Schram, J. Z. Naturforsch. 1999, 54, 155-164. (b) Since $\mathrm{HCl}$ was mostly dispersed in water, a $\mathrm{pH}$ value of 4 can be estimated if we take into account the total volume of water as $0.11 \mathrm{~mL}$. At such a low $\mathrm{pH}$ value, the hydrolysis rate constant for HDTMS is $1.04 \mathrm{~h}^{-1}$ (ref 17a), suggesting $96 \%$ of the molecules becoming silanols at the end of $3 \mathrm{~h}$. (c) The relative increase in the intensity of the $\mathrm{R}$ structure from $t i=1 \mathrm{~min}$ to $6 \mathrm{~h}$ is qualitative. While the films were prepared with exactly the same procedure, the final film thickness and surface area of the specimen probed by the X-ray beam cannot be accurately controlled and may have contributed to the change in intensity.

(18) Tímár-Balázsy, Á.; Eastop, D. Chemical principles of textile conservation; Butterworth-Heinemann: Woburn, MA, 1998.

(19) Bourlinos, A. B.; Chowdhury, S.; Jiang, D. D.; An, Y.; Zhang, Q.; Archer, L. A.; Giannelis, E. P. Small 2005, 1, 80-82.

(20) Osman, M. A.; Seyfang, G.; Suter, U. W. J. Phys. Chem. B 2000, 104, 4433-4439.

(21) Beari, F.; Brand, M.; Jenkner, P.; Lehnert, R.; Metternich, H. J.; Monkiewicz, J.; Siesler, H. W. J. Organomet. Chem. 2001, 625, 208-216.

(22) Ang, T. P.; Wee, T. S. A.; Chin, W. S. J. Phys. Chem. B 2004, 108, 11001-11010.

(23) Yilgor, I.; Yilgor, E. Polym. Bull. 1998, 40, 525-532.

(24) Badia, A.; Lennox, R. B.; Reven, L. Acc. Chem. Res. 2000, 33, 475-481.

(25) Daoud, W. A.; Xin, J. H.; Tao, X. Appl. Surf. Sci. 2006, 252, 5368-5371.

(26) Jursic, B. S. J. Chem. Soc., Perkin Trans. II 1999, 369-372.

(27) Walsh, R. Bond Dissociation Energies in Organosilicon Compounds. http://www.gelest.com/Library/10BondDiss.pdf (Accessed 06/13/10).

(28) Luo, Y. Handbook of Bond Dissociation Energies in Organic Compounds; CRC Press LLC: Boca Raton, FL , 2002.

(29) De Prado, L. A. S. A.; Torriani, I. L.; Yoshida, I. V. P. J. Polym. Sci., Part A: Polym. Chem. 2010, 48, 1220-1229. 


\title{
Supporting Information
}

\section{Supramolecular Nanolayer Reconfiguration after Molecular Intercalation}

\begin{abstract}
Alexandre Dhôtel, ${ }^{\dagger}{ }^{\ddagger}$ Hui Li, ${ }^{\S}$ Lucia Fernandez-Ballester, ${ }^{*} \dagger$ Laurent Delbreilh, ${ }^{\dagger}$ Boulos Youssef, ${ }^{\ddagger}, \|$ Xiao Cheng Zeng, ${ }^{\S}$ and Li Tan ${ }^{*}, \dagger$

${ }^{\dagger}$ Advanced Mechanics and Materials Engineering (AMME) International Laboratory, ATEAM, Department of Engineering Mechanics and Nebraska Center for Materials and Nanoscience, University of Nebraska, Lincoln, Nebraska 68588, United States

${ }^{\ddagger}$ Advanced Mechanics and Materials Engineering (AMME) International Laboratory, LECAP, Institut des Matériaux de Rouen, Faculté des Sciences, Université de Rouen, Site du Madrillet, 76801 Saint Etienne du Rouvray Cedex, France

${ }^{\S}$ Department of Chemistry, University of Nebraska, Lincoln, Nebraska 68588, United States

"Institut National des Sciences Appliquées de Rouen (INSA), Avenue de l'Université - BP 08, 76801 Saint Etienne du Rouvray Cedex, France
\end{abstract}
A. X-Ray Diffraction (XRD)
B. Atomic Force Microscopy (AFM)
C. Differential Scanning Calorimetry (DSC)
D. Illustration of Siloxane Condensation between TMOS and HDTMS 


\section{A. X-Ray Diffraction (XRD)}

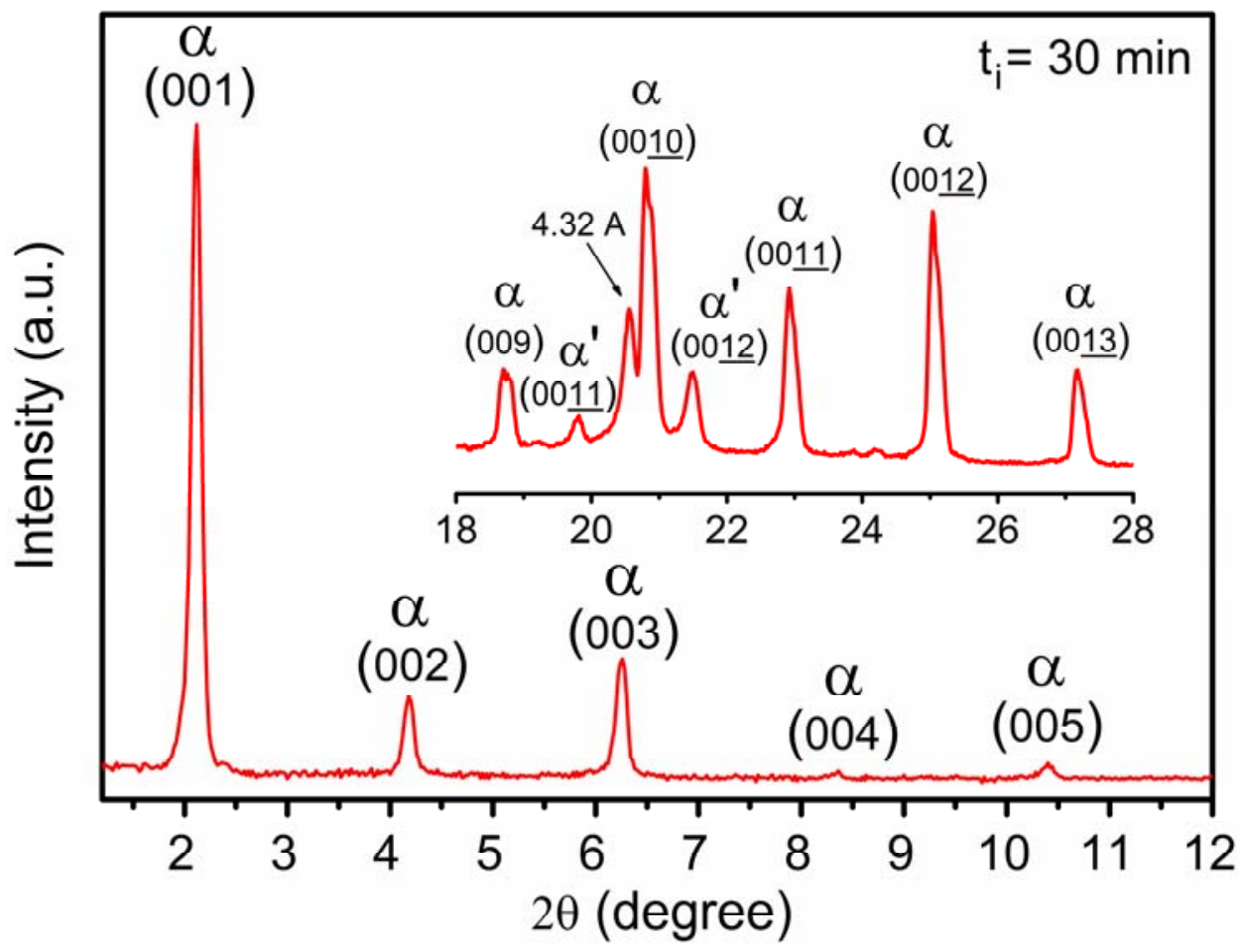

Figure SI-1: SAXS and WAXS (inset) spectra showing higher order diffraction peaks of the $\alpha$ and $\alpha^{\prime}$ layers in HDTMS + TMOS films when the intercalation time, $t_{i}$, is equal to $30 \mathrm{~min}$. 


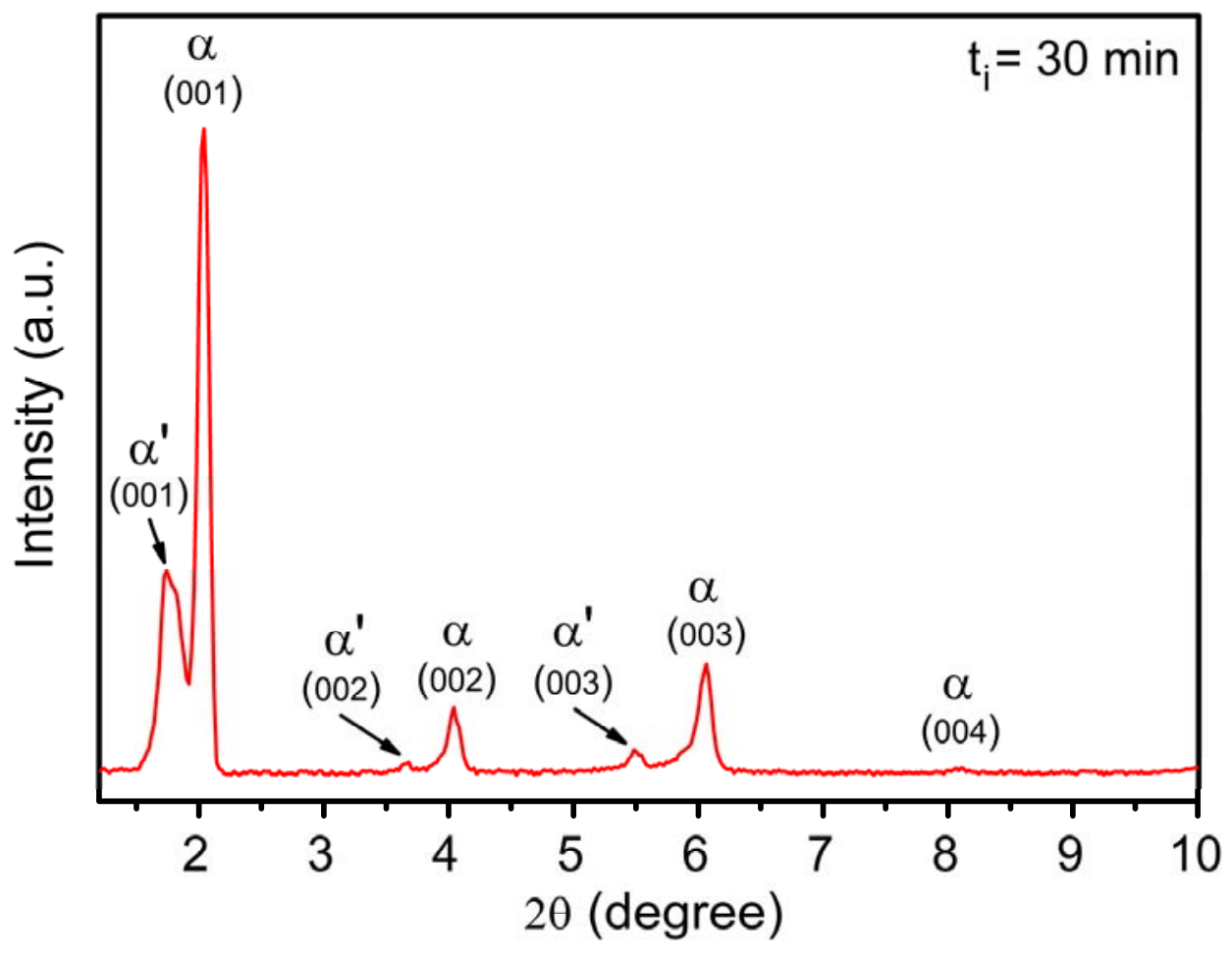

Figure SI-2: SAXS pattern of thick HDTMS + TMOS film composed of $\alpha$ and $\alpha$ ' layers when the intercalation time $t_{i}=30 \mathrm{~min}$. 


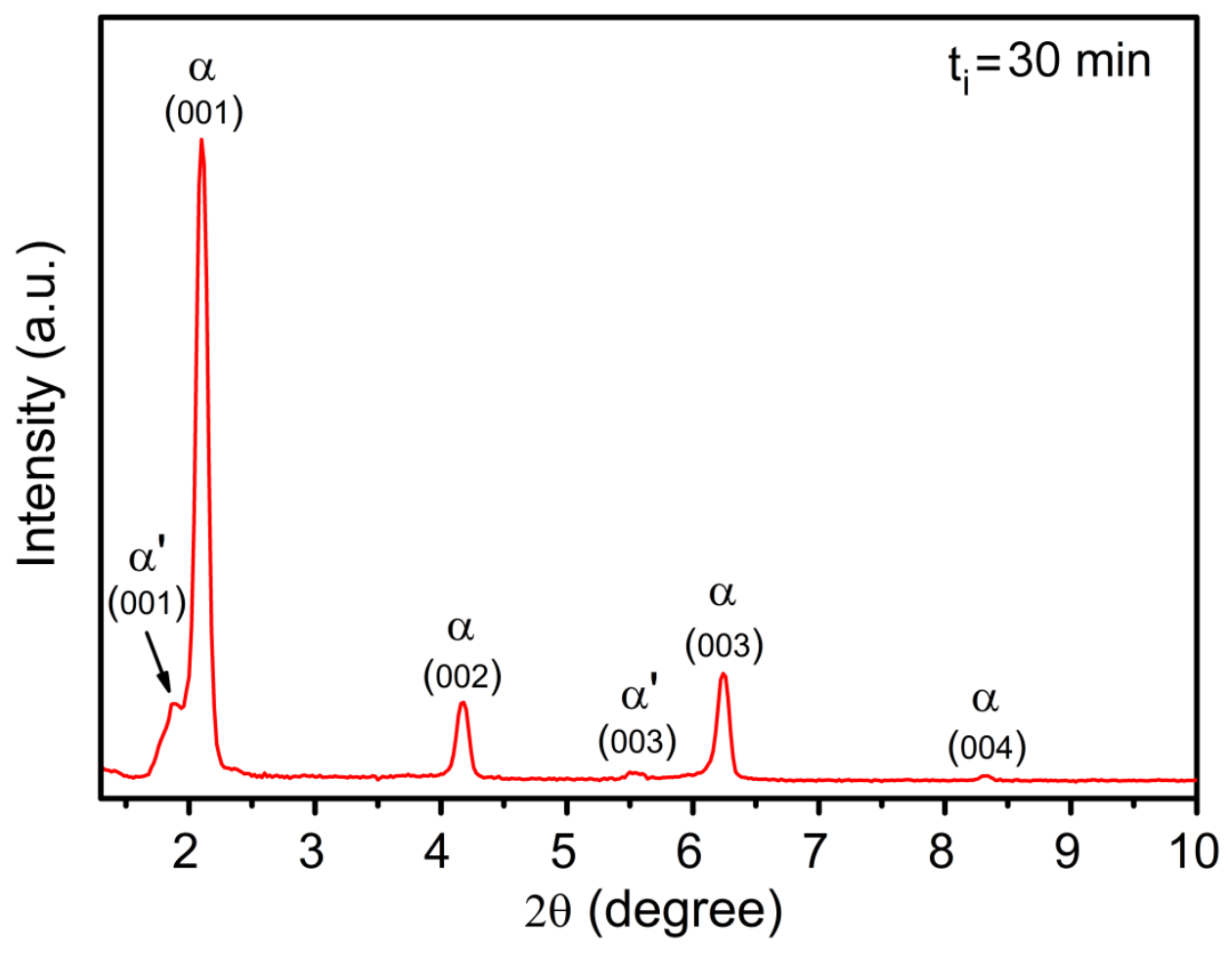

Figure SI-3. Small angle XRD spectrum of thick films of control nanolayers composed only of pure HDTMS molecules (no TMOS was added) for $t_{i}=30$ minutes. The film is composed of two structures $\alpha$ and $\alpha^{\prime}$. The thickness of the film explains the presence of the $\alpha$ ' layers. 


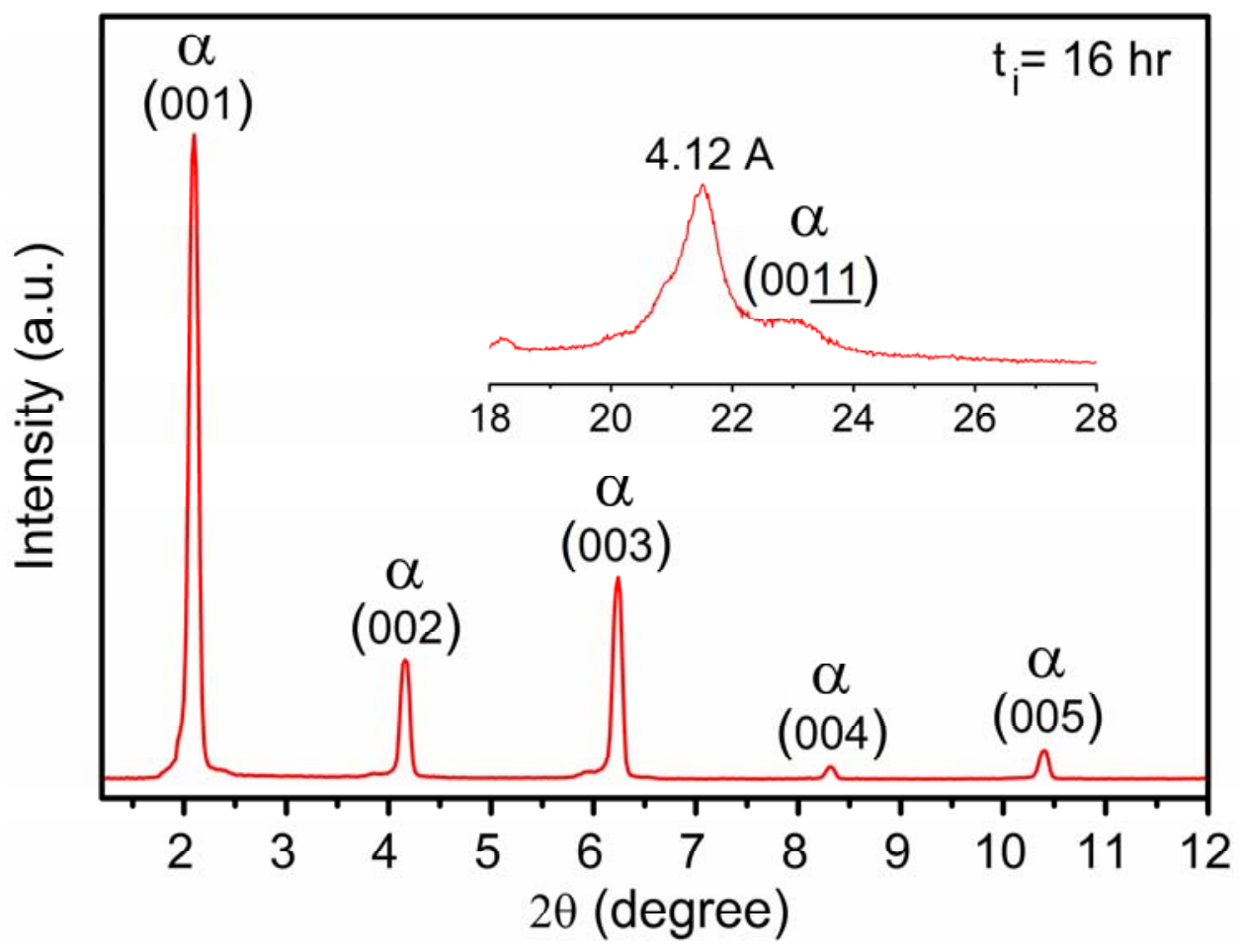

Figure SI-4. Wide (inset) and small angle XRD spectra of thin control films of nanolayers formed by HDTMS molecules only (no TMOS was added) for $t_{i}=16 \mathrm{hr}$. The pattern is similar to the one obtained on a HDTMS+TMOS film with for $t_{i}=30$ minutes. The only difference is in the inset graph, where a broad peak at $2 \theta \sim 21.2^{\circ}$ is found corresponding to the spacing between alkyl chains. The broader width of this peak indicates that some condensation of inorganic moieties has occurred, which further distorted the ordering of the organic moieties. 


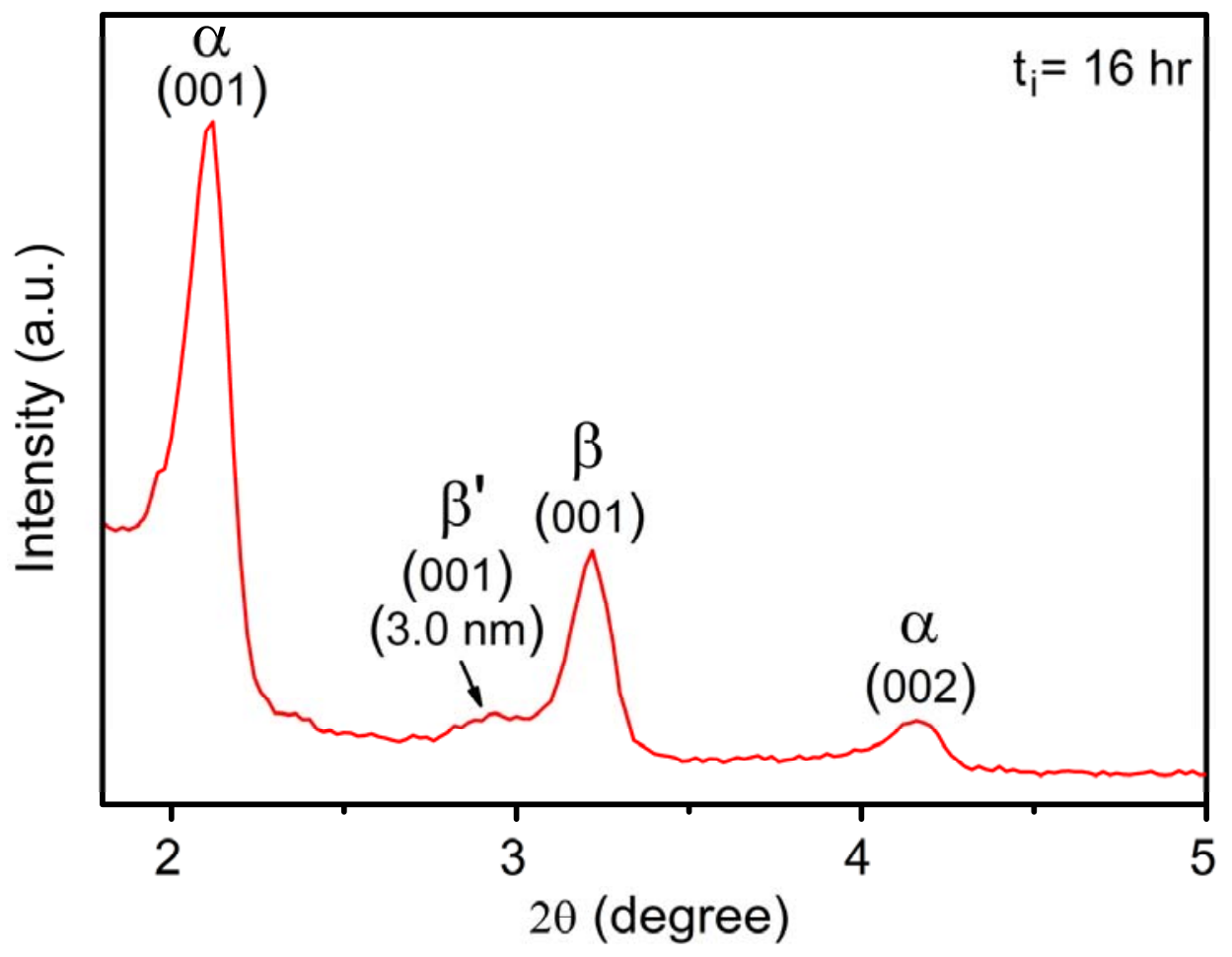

Figure SI-5. Zoom-in of the top curve in Figure 2a. SAXS spectrum of thin HDTMS + TMOS films $\left(t_{i}=16 \mathrm{hr}\right)$ revealing the $\beta$ ' layers $\left(2 \theta \approx 2.92^{\circ}\right)$ formed of slipped $\beta$ layers. 


\section{B. Atomic Force Microscopy (AFM)}

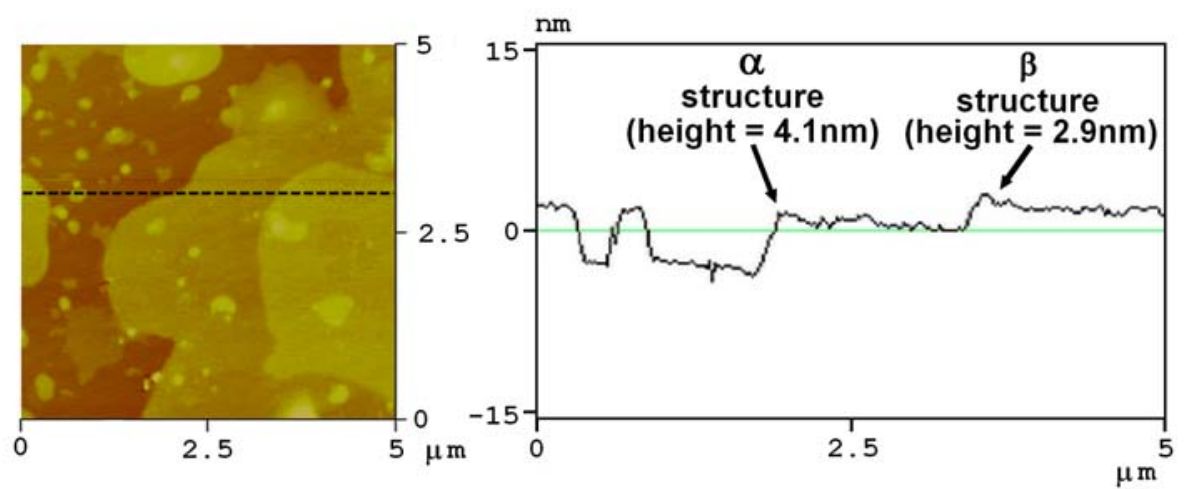

Figure SI-6. AFM images confirm and highlight the stacking of nanolayers with more than one stacking mode. The left image is a topography corresponding to the height reliefs on the surface of the film, where the cursor profile showing depth of individual layers (right image). Different heights suggest the stacking of an interdigitated layer $(\beta)$ above a bilayer $(\alpha)$. The sample is a HDTMS + TMOS film, where TMOS was given $16 \mathrm{hr}$ for intercalation. 


\section{Differential Scanning Calorimetry (DSC)}

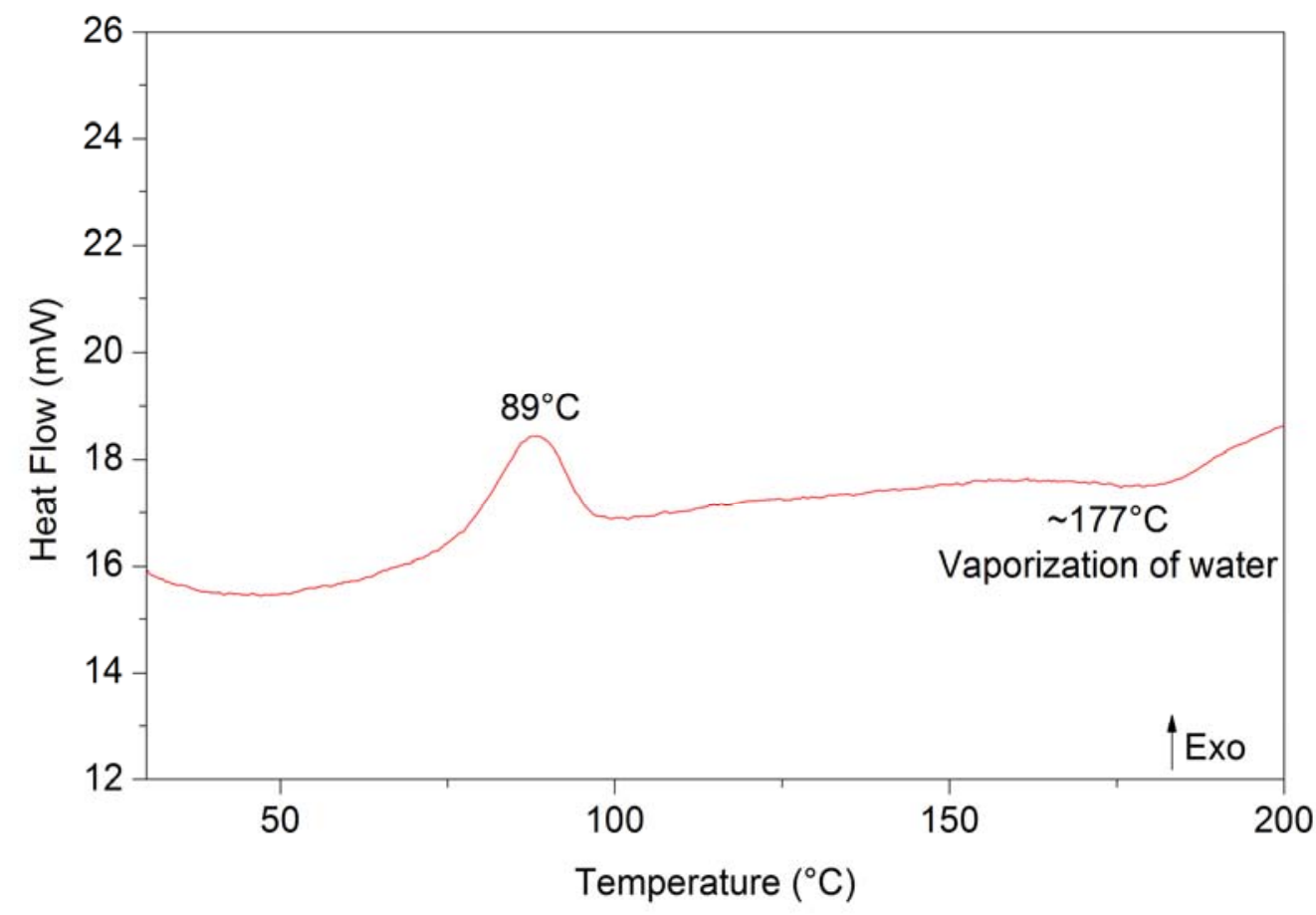

Figure SI-7. Differential Scanning Calorimetry (DSC) spectrum of a HDTMS + TMOS film, where the molecular additive (TMOS) was given $30 \mathrm{~min}$ of intercalation into HDTMS aggregates. The endothermic peak at $\sim 177^{\circ} \mathrm{C}$ is assigned to the release of water molecules formed by the condensation of Si-OH residues. The exothermic peak at $89^{\circ} \mathrm{C}$ is assigned as a hydrolysis of silanes (-SiOR) to silanoles $(\mathrm{Si}-\mathrm{OH})$ by releasing methanol and water. This peak explains the presence of a degradation peak at $90^{\circ} \mathrm{C}$ on TGA spectrum. 
D. Alcohol condensation reactions

HDTMS alcohol condensation:

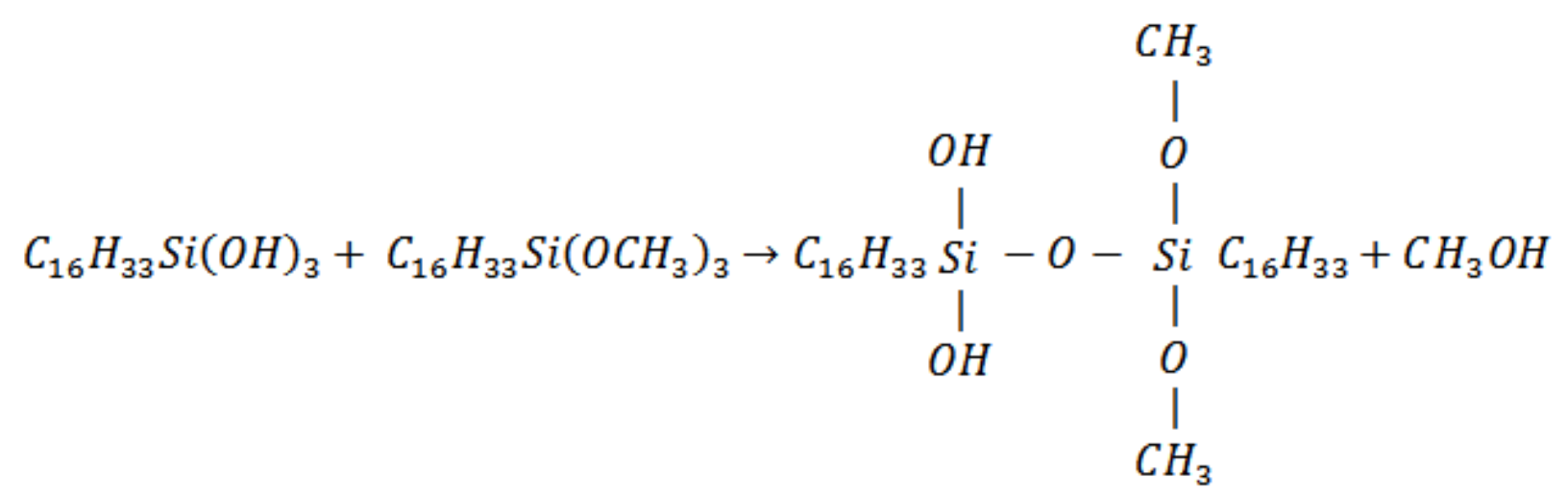

TMOS alcohol condensation:

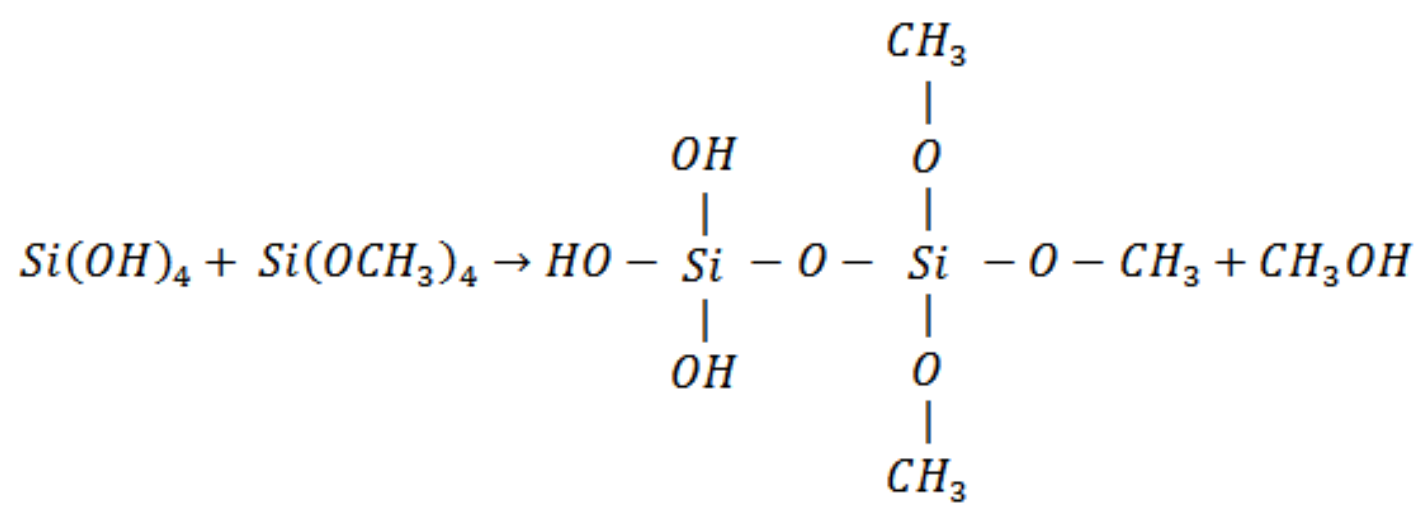

